\title{
The ethnopragmatics of Akan advice
}

\author{
Kofi Agyekum \\ University of Ghana, Legon
}

This paper discusses Akan Advice under ethnopragmatics. It adopts persuasion, speech acts of directives and expressives, and Akan proverbs to discuss advice with the insight from Akan culture. The adviser expresses some feelings and emotions and directs the advisee to act and behave towards the benefits of the individual, the group or society. The paper taps data from participant observations and audio taped recordings at arbitrations, marriage and naming ceremonies. There is another data from Adi's (1973) Akan literature book, Brako that covers pieces of advice on travelling, settlement and occupation. The Akan texts are translated into English and analysed. The analysis covers semantics, pragmatics, stylistic devices, and proverbs.

Keywords: Akan, advice, ethnopragmatics, cultural scripts, directives, expressives, persuasion, proverbs

\section{Introduction: Linguistic routines}

This paper is a contribution to Akan ethnography of communication, ethnopragmatics and discourse analysis. It adds to works on Akan linguistic routines and language of social interactions by Agyekum (2010, 2008, 2006a, 2006b, 2005, 2004a and 2004b), Obeng (1999) and Yankah 1995, and Ameka (2009, 2006) and Ameka and Breedveld (2004) on Ewe ethnopragmatics. Agyekum worked on the sociolinguistics, linguistic routines and ethnopragmatics of Akan thanking, greetings, apology, requests, personal names, concept of face and persuasion. Obeng worked on apologies, and Yankah on proverbs and orality.

The paper will specifically draw attention to the use of proverbs, persuasion, directives and expressives in Akan advice, and what constitutes an advice from the standpoint of Akan culture and ethnopragmatics. The paper further highlights the Akan ethnographic situations that trigger the use of advice. This study on advice aspires to contribute immensely to the Akan research on linguistic routines, ethnopragmatics and ethnography of communication. 
Advice is one of the linguistic routines in the sequential organisations of interactional rituals in people's everyday interaction (see Agyekum 2010, 2008, 2006a, 2005). Among the Akans, the most outstanding linguistic routines are greetings, apology, request, thanking, compliments, advice and recounting of one's mission. Akans expect members to perform these with the highest degree of communication-in-performance. They form part of children's enculturation, socialisation, and communicative competence. Agyekum $(2010,78)$ opines that

\begin{abstract}
"Communicative activities are carried on daily in a speech community and the activities involve certain linguistic items accompanied by performance." These routines fall under performatives and speech acts and are performed in relation to the socio-cultural norms and networks of the society. The linguistic routines are communally owned and predictable, and interlocutors are expected to follow certain accepted societal and cultural formulas and conventions.
\end{abstract}

In language learning and acquisition, one must have mastery of the sociopragmatics of the target language and culture, speech acts and linguistic routines (see Agyekum 2010, 2008).

The paper is organised into the following; an introduction, information on the Akan people and language, the methodology, the theory of ethnopragmatics, speech acts used in advice, and the Akan concept of advice. The fourth section addresses the ethnographic contexts for the use of advice, and section 5 analyses a piece of advice from a selected book focusing on proverbs.

\title{
1.1 The Akan language and people
}

The word 'Akan' refers to the people as well as their language. Akan can be considered from (a) ethnographic and (b) linguistic, perspectives. The ethnographic Akan includes Ahantas, Aowins, Nzemas, and Sefwis who do not speak Akan as L1 but shares cultural similarities with the Akans (Obeng 1987). ${ }^{1}$ The linguistic Akans are those who speak Akan as their L1. Akans are the largest ethnic group in Ghana. In the 2010, national population census, $47.5 \%$ of the Ghanaian population was Akan and about $44 \%$ of the rest speaks Akan as non-native speakers.

The Akans occupy the greater part of southern Ghana. Akan is spoken as a native language in nine out of the 16 regions in Ghana namely Ahafo, Ashanti, Bono, Bono East, Central, Eastern, Oti, Western and Western North Regions. The Akan speaking communities in the Oti Region are sandwiched by the Ewe communities. The Akan dialects are Agona, Akyem, Akuapem, Akwamu, Asante,

1. All the languages spoken by the ethnographic Akans are genetically related to the Akan language (see Obeng 1987) 
Assin, Bron, Buem, Denkyira, Fante, Kwawu, Twifo, and Wassaw dialects. Some Bron speakers are found in Cote d' Ivoire. Akan is studied from primary school up to the university.

\subsection{Methodology}

Some of the data on advice were tapped from participant observations at certain ethnographic communicative events like naming, marriage ceremonies and arbitrations at the chief's court. I was invited to these ceremonies, observed and took part in the deliberations. As an Akan ethnographer, I always attend these functions with my tape recorder, phone and note pads ready to collect rich data, because I do not want to miss such ethnographic events. Most of the data were audio-taped with my phone; for some of them, I got copies of the video from the camera men hired to capture the events.

Some of the data for this paper is chosen from an Akan literature book entitled Brako by Adi (1973). This book was selected on the basis of fair representations of pieces of advice that have didactic functions. It has been used as a set book for the West African Examination Council (WAEC) for many years. It is read in secondary schools, training colleges and even at the Akan departments in the universities. The book was again used on Kenkan Me, a Reading programme on Peace FM. I further consulted books and articles on ethnopragmatics, speech acts, persuasion and advice.

The Akan texts are provided and translated into English. The data was analysed holistically by looking at the lexicon and semantics. We analysed the pragmatic and discourse features, figures of speech, especially, proverbs, metaphors and symbolisms. I analysed the contents of the pieces of advice based on Akan ethnopragmatics, looking at narratives and cultural analogies that are useful for Akan advice. The research questions that guided this study are:

a. What is the role of ethnopragmatics, persuasion, directives and expressives in the study of Akan advice?

b. What constitutes Akan advice and how different are they from English?

c. What are the Akan ethnographic situations that call for advice?

d. Why are proverbs essential parts of Akan advice? 


\section{Ethnopragmatics}

Goddard and Ye $(2015,66)$ posit that

Ethnopragmatics designates an approach to language in use that sees culture as playing a central explanatory role, and at the same time opens the way for links to be drawn between language and other cultural phenomenon.

According to them, the approach to ethnopragmatics involves a three fold alignment of objectives, methodological tools and evidence base as seen below.

The objective of ethnopragmatics is to articulate culture-internal perspectives on the "how" and "why" of speech practices in diverse languages. It describes and explains people's way of speaking that makes sense to them in terms of indigenous values, beliefs, attitudes, social categories, emotions, etc. (see Goddard 2006,2). The methodological tools are based on decomposing cultural notions and capturing cultural norms in terms of simple meanings that appear to be shared between all languages. i.e., cultural scripts and indigenous labels. Ethnopragmatics pays particular attention to linguistic evidence, e.g. using patterns that are discoverable, corpus techniques, interactional routines, language specific lexico-grammatical constructions, etc. In this paper, advice is an evidence of Akan interactional routine.

Linguistic usage functions as an index of routine ways of thinking, and when appropriately analysed, it draws us closer to "insider perspectives' of the participants (see Goddard 2006,3, 11). Goddard and Ye $(2015,80)$ looks at the contribution of ethnopragmatics in the area of language endangerment and posit that ethnopragmatics provides techniques for capturing indigenous concepts and describe speech practices effectively, free from Anglocentrism (see Goddard 2006, 17; Wierzbicka 2012,309).

Ethnopragmatics explains speech practices, which begin with culture-internal ideas; these include the shared values, knowledge, norms, priorities, and speakers' assumptions instead of any presumed pragmatic universals (see Goddard 2004). Sharifian $(2017,52)$, posits that "The knowledge that underlie the enactment and uptake of speech acts is part of that (shared) knowledge." The Akan speech act of advice is a shared knowledge by interlocutors. Ethnopragmatics is close to cultural linguistics from the standpoint of Sharifian $(2015,473)$, who sees cultural linguistics as multidisciplinary area of research that explores the relationship between language, culture, and conceptualisation. Goddard $(2006,2)$ opines that

Ethnopragmatics is necessarily intertwined with cross-linguistic semantics because the whole idea is to understand speech practices in terms, which make 
sense to the people concerned, i.e., in terms of indigenous values, beliefs and attitudes, social categories, emotions, and so on.

Language-specific semantic notions are discussed using cultural scripts as we find in Ameka (2009), Ameka (2006), Ameka and Breedveld (2004), Goddard and Wierzbicka (2004), and Wierzbicka (2015). Goddard $(2006,11)$ avers that "Cultural scripts allow us to "unpack" culturally shared understandings of particular "ways with words" from an insider-perspective, without recourse to such technical and language-specific labels." Goddard $(2006,12)$ further posits that "Cultural scripts can be employed to spell out widespread cultural beliefs - beliefs which may be profoundly explanatory of aspects of communicative practice." Cultural scripts are essential in ethnopragmatics and ways of speaking. Goddard and Weirzbicka $(2004,153)$ posit that

The term cultural scripts refers to a powerful new technique for articulating cultural norms, values, and practices in terms which are clear, precise, and accessible to cultural insiders and to cultural outsiders alike.... The different ways of speaking of different societies are linked with and make sense in terms of different local cultural values, or at least, different cultural priorities as far as values are concerned. Cultural scripts exist at different levels of generality, and may relate to different aspects of thinking, speaking, and behaviour.

Ameka and Breedveld (2004), employed cultural scripts as a technique in ethnopragmatics to effectively discuss ways of speaking and social interaction among the Ewes in West African and the Fulfulde in Sudan. They discussed taboos, use of personal names, address terms, leave taking, use of intermediaries in communicative interaction and name avoidance. Ameka (2006,321-323) discussed the ethnopragmatics of speech formulas for "gratitude" among the Ewes, Akans, Likpes and Bulis from Ghana. He showed how these languages presuppose deeply culturally embedded values and beliefs about death and how the rituals like gratitude and greetings are employed as routines. Ameka $(2006,259)$ summarised that "the understanding and interpretation of speech formulae depend on cultural knowledge and shared beliefs, attitudes and values." Ameka (2009), further used cultural scripts to discuss the categories and social dynamics of access rituals in West African societies. The emphasis was on Ewe and Akan farewell, greetings, social visits, thanking, and amannebs, 'inquiry about the purpose of one's visit.

\subsection{Advice in Akan ethnopragmatics}

In the ethnopragmatics of Akan advice, the adviser initiates a message and the advisee reacts based on their common folk knowledge and understanding. In Akan advisory speech act, in Section 4.4, a junior should not react verbally to 
adults' advice, but should behave accordingly. The reaction from the advisee could be positive or negative. It is positive, if the speaker persuades the advisee to understand and appreciate the essence of the advice and gladly receive it. Naturally, the adviser's intention is to win the advisee to his side.

In the Akan ethnopragmatics of advice, interlocutors normally respect the views of each other as social individuals and same cultural group insiders. The adviser does not seek his self-interest at the expense of his advisee, because both are social players in the interaction aiming to get something better for the advisee and the society. Participants in the advisory interaction should be mindful of the natural and common socio-cultural environments in which they operate, and adapt themselves effectively to the ever-changing environment, the human conditions and the Akan socio-cultural norms.

The goal of the Akan adviser is to exert some "potential" influence on the advisee using expressives, directives, persuasion and proverbs without denigrating him/her. The adviser should persuade the advisee by handling face saving and face-threatening mechanisms cautiously. This is done by using indirection and politeness, especially by prefacing the advice with proverbs to indicate their authoritative sources. In Section 4.4, instead of directing the advisee to refrain from misconduct, the father used the proverb (no.5) animguasee mfata skanni ba, 'disgrace does not befit an Akan citizen'. Let us briefly look at expressives, directives and persuasion.

\subsection{Expressives and directives in advice}

Expressives and directives are very relevant in the discussion of Akan advice because advice is primarily listed under directives (see Duranti 1997). Advice can be an expressive because the adviser expresses his feelings about something he finds about the advisee from the innermost part of his heart.

\subsubsection{Expressive in advice}

Expressives are representatives and interpretations of the psychological inner state of the speaker, either to himself or to the addressee. They indicate that the speaker is expressing an inner feeling towards something which s/he deems to be true, and which s/he is sincerely expressing an opinion. Expressives denote statements of pleasure, pain, likes and dislikes, joy, sorrow, love or hatred (see Mey 2001, 121; Yule 2000,53). Expressive verbs include apologise, thank, condole, congratulate, complain, lament, protest, deplore, compliment, praise, welcome and greet (see Duranti 1997).

From the list above, we argue that an adviser expresses a feeling by either complaining, lamenting, protesting, or deploring about a state of affair that he 
finds in the advisee, which must be eradicated or changed for the better. Advice is subjective and it depends on the adviser and how he conceptualises the behaviour of the advisee within the Akan sociocultural context. Akan directives and expressives in advice are based on Akan sociocultural rules and norms of interaction. If an advisee pays heed to advice and transforms his behaviour, it benefits him and the entire society. The verbal expressives are complemented by facial expressions and gestures that help the advisee to better interpret the adviser's intention, and for the adviser to interpret the advisee's (non)-verbal reaction (Agyekum 2010, 78).

\subsubsection{Directives in advice}

Some parts of advice communicative events are directives expressing what the speaker wants the addressee to do. Directives include commands, orders, advice, requests, proposals, and suggestions (see Duranti 1997,223; Yule 2000,54). Searle $(2009,1004)$ avers that:

Directives are those kinds of speech acts that represent attempts by the speaker to get the addressee to do something. They express the speaker's desire/wish for the addressee to do something. Paradigmatic cases include advice, commands, orders, questions, and requests. In using a directive, the speaker intends to elicit some future course of action on the part of the addressee, thus making the world match the words via the addressee.

In Akan, there is a high degree of interdependency and communalism; advice may thus not be seen as a strong imposition and face-threat on the advisee (Obeng 1999, 231). That is why in Section 5.1, the father prefaces the proverbs with "advisory verbs". The adviser can order, request or plead to the advisee towards a posterior event and this pertains to Akan pieces of advice. Some Akan pieces of advice may inconvenience the advisee but the Akan social respect, obedience and politeness systems abhor the advisee to instantly refuse the advice. The degree of facethreat may depend on the ethnographic setting, the participants, how the advice is couched and rendered before the advisee. However, there are situations in the Akan modern society, as seen in Excerpts 1 and 2, where the advisees come out boldly to decline the advice.

\subsection{Persuasive language in advice}

We are discussing persuasion here as a perlocutionary effect and the impact on the advisee that engenders him to respond to the advice. Persuasion is the attempt to cause a person to act in a certain way sometimes against his normal will (Agyekum 2004b). The persuader engenders action(s) towards a change in the behaviour or mind of the persuadee. In an advisory persuasion, the adviser wants 
the advisee to fulfill his/her intentions. Agyekum (2004b) noted that the adviser's persuasive language can move the advisee to act favourably to provide harmony between them for the message to be well received. The persuader's task is to establish or strengthen a social relationship and maintain co-operation among participants in the Akan advisory event.

\subsection{The Akan concept and definition of advice}

In Akan, advice refers to suggestions, opinions and ideas that a Speaker provides to an Addressee to show concern, admiration, interest and disapproval on certain crucial issues within a specific ethnographic context. Wierzbicka (2012,310) alludes that there are quasi-synonyms for advice in English including counselling, offering counselling, recommending, exhortation, or admonition. She argues that this cannot represent the notion of advice in all languages therefore there is the need to capture the core meaning based on natural semantic metalanguage, that will be applicable to all languages. Advice embodies a particular culture-specific configuration; hence what could be labelled as advice in one culture may not necessarily be so in another. ${ }^{2}$

Wierzbicka $(2012,310)$ thus proposes that "A universally cross-translatable mini-language in which the proposed conceptual anchor for discourses of "advice" has been formulated is "it will be good if after this you do this". This is a conceptual yardstick that can semantically cater for advice in cross-linguistic and cross-cultural comparisons. Wierzbicka $(2012,321)$ states that "in English advice implies a perception on the part of the speaker that the addressee is in some sort of uncertainty as to what she or he should do, and the person who offers advice responds to that perceived uncertainty."

In Akan, advice normally shows the acquaintances, solidarity, rapport, intimacy, and "group belongingness" of the interlocutors. Due to the Akan communal nature, advice is part of our sociocultural values. In most cases, pieces of advice are unidirectional emanating from adults to children, higher-ups to subordinates, the rich to the poor, and not the reverse. ${ }^{3}$ It could be "mutual advice" between hus-

2. We are using the Akan term afotuo to capture many communicative aspects in naming ceremony and arbitrations, which may not fall under advice in English.

3. Situations of advice-giving are inherently loaded with varying degrees of variables such as intimacy, power and urgency, that determine how directly the addressee can formulate the advice in an urgent situation, a piece of direct or unsolicited advice such as You'd better not drive so fast, might be warranted in English. However, where the addresser has much less power or status than the addressee, the piece of advice must be couched in mitigating language (Tsurikova and Evanson 1995, 18). 
band and wife or co-workers of the same rank. Most Akan pieces of advice are formulaic and predictable. For instance, pieces of advice given after the settlement of cases at the palace are routinised, and one can predict what the chief's spokesperson will say after the verdict. After the settlement of a dispute there is what I will term "bi-advice" where both the innocent and the guilty parties are advised to live in harmony and forget about what had happened. After marriage contract, the elders' advice to the bride and the bridegroom are predictable. Excerpt 1 was audio-taped at a marriage ceremony in Accra on 2nd May 2015 that I participated, I used my android phone.

\section{Excerpt 1.}

MonkJtena asomdwoesm na momm brapa nwo mmapa. Monntietie atessm, na montwe mo ho mfiri aysnkogor mu.

'You should go and live peacefully and put up a decent life and produce good children. Don't listen to rumours; run away from excessive friendships.'

In Akan, some people consider advice as face-threatening since it may admonish the advisee, but it is good to his welfare and the group. Let us see Excerpt 2.

\section{Excerpt 2.}

In Accra, a professor of a university has seen that his friend, a 46 year old who is gainfully employed is engaged in alcoholism. He advised him to stop since it does not befit his status. The advisee retorted as follows

"Is it your business to advise me? Are you the one who buys the drinks for me? How can you advise me to stop at once? Have you ever seen a car in the 5 th gear that has suddenly been shifted into 1 st gear?

The above excerpt was recorded on tape in June 2017 at the office of the professor when his friend visited. This is an advice to someone who has become addicted to alcohol. The advisee thinks that the adviser is impinging on his freedom of action. Due to the face-threatening nature of advice, sometimes pieces of advice are not adhered to, especially when they bother on change of addictive attitudes in the addressee's life. Advice should thus be given with some diplomacy, persuasion, politeness and indirection.

Sometimes, advisees find it difficult to accept advice especially when they feel that they are matured enough. They want their privacy, and feel very frustrated and uncomfortable; they believe that they could make their own decisions and need no naggings and intrusions.

\section{Excerpt 3.}

In Accra, on 24th July 2016, Mr. Mensah a 63 year old retired civil servant invited me to his residence to help advise his son, Kwadwo, who is gainfully employed but has engaged himself in alcoholism. The father advised him strongly to refrain from it 
since his acts affect and disgrace the entire family. The son's response was, "I am a grown up, I can manage my own affairs. You cannot influence me; allow me to operate on my own." He then walked away disregarding the father and me (the visitor). [I immediately wrote the interaction].

Jefferson and Lee $(1981,405)$ found that even in contexts of troubles-telling in English, the giving of advice is a precursor of dispute, and is rejected in most of such interactions. Wierzbicka $(1991,30)$ compared the Russian, Serbo-Croatian, Polish and Spanish languages with the English social interactions. She concluded that the English-speaking tradition, places special emphasis on individual rights and autonomy and thus abhors any interference in other people's affairs. The tradition respects everyone's privacy, and approves of compromises, and disapproves of dogmatism. Advice-giving, generally has a negative socio-cultural and interactional value, and can be perceived as intrusive and overbearing. However, in Akan culture, as in Russian and other Slavic cultures, advice, invitations and suggestions are often imposed on the interlocutor. In Akan, pieces of advice are normally direct and imposing, but the socio-cultural norms imbibe advisees to accept them (see Section 4.3).

Normally, the Akan adviser has all the good-will, and wants the welfare of the advisee; he considers the potential benefit to the advisee, hence the advice could be direct and imposing (see Tsurikova and Evanson 1995, 17).

\section{Ethnosemantics of afotuo, 'Advice' in Akan}

The word afotuo is derived from the verbal phrase $t u+f o$, which are transposed into fotu, plus the nominal prefix $a$ - and the suffix -o to derive afotuo, which means advice, suggestion, exhortation or admonition. The agentive form is Jfotufor, 'adviser, counsellor, exhorter, and admonisher'; we have afotusem (afotu + ascm), which refers to the message in advice. In Akan Christian literature, afotusem is a sermon meant to advise and admonish Christians to put up good behaviour. The shorter form of afotuo is $\varepsilon f o$, advice, counsel' as in the example $\varepsilon f o$ bone ben na Jretu wo? What bad advice is he giving you? The part fo is derived from the nasalized form $f \tilde{o}$, 'nasty, bad, worthless, despicable, useless, spoiled, ruined, desolate', etc (see Christaller 1933,130). Hence, $t u$, 'remove, dig', + fo, 'nasty', means, remove the useless element in the person. When we advise people, we normally want to shape and filter their characters or skills towards better forms for their benefit, the group and the society.

Among the Akans, afotuo, 'advice' covers drawing people's attention to both positive and negative attitudes. We can advise somebody to refrain from doing 
something negative. On the contrary, advice could be extended to cover an encouragement, a positive directive to pursue a venture, or drawing people's attention to Akan socio-cultural norms and values. Thus, what is considered an advice in Akan may not be describable as an advice in a language like English. A typical example is what is recorded in Excerpt 4 at a naming ceremony. We can even consider an appeal to the ancestors as a form of advice in Akan.

The concept of advice in Akan is similar to what Larina $(2009,254)$ describes about the Russians as follows "In Russian culture 'advice' (sovet) is traditionally perceived not as intrusion in someone else's personal life, but as help. It is given with best intentions, without any fear of damaging the interests of the interlocutor, who will understand the speaker's motivation and accept the 'advice' (sovet) with gratitude." (See Wierzbicka 2012,319). Wierzbicka (2012) states the core of advice in NSM as "it will be good if after this you do this." This calls for a change for the better.

\subsection{Akan proverbs and maxims on advice}

The most acknowledged and cherished element of Akan communicative competence is the use of $\varepsilon b \varepsilon$, 'proverbs' in speech, and they are therefore employed in advice. Proverbs are interpretations of traditional wisdom based on the experiences and socio-cultural life of our elders. There are Akan maxims on advice that have been time-tested and found to be true. They are based on the people's experiences, philosophy, religion and cultural ideology (see Agyekum 2012 on the role of proverbs in marriage).

In Akan, there are adages such as $\varepsilon b \varepsilon$ ne skasa mu abohemmaa, 'the proverb is the most precious stone of speech', $\varepsilon t w a$ as $m$ tia, 'it curtails matters', $\varepsilon n k a$ asem ho $a$, हnwie $d \varepsilon y \varepsilon$, 'without it, a speech does not acquire its sweetness'. Akans perceive proverbs as an aesthetic device of vitality in speech and an indispensable salt of a language, without which the "language dish" loses its real taste.

A competent Akan speaker intersperses his speech with proverbs and such a speech form is considered an adult style. The intensive use of proverbs is based on the predominant Akan face-to-face communication (Yankah 1991, 1989). To avoid the risk involved in such ritual interaction, a competent adviser, uses proverbs as a persuasive device to convince his advisee to listen and comply. An Akan speaker can use multiple proverbs within the same discourse to highlight the value of the message and depict his politeness level to handle face-threatening acts. Let us consider two of them. 


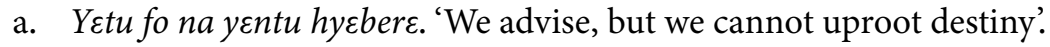
In Akan philosophy, the society has no hand in destiny; it can only advise people on social or physical things but not on destiny which is metaphysical. This maxim is quoted when one does not yield to consistent advice, and the society becomes fed up. Advice is very important but the advisee is not obliged to conform, especially when he considers it as an infringement on his private life.

b. Afotuo nsakra onipa gye se nşhwe. 'Advice does not change a person but rather suffering. Some people do not pay heed to pieces of advice, but when in trouble, they are compelled to listen. A drunkard may not listen to advice to abstain from drunkenness but if he is diagnosed with cancer due to drunkenness, he will adhere to advice.

\section{Ethnographic contexts for advice in Akan}

As a linguistic routine, advice is given from cradle to grave. Akans advise the visible and the invisible, the living and even the dead, children and adults. In this section, we will discuss pieces of advice recorded from sociocultural communicative events like naming ceremonies, marriages, travelling, recruitment into a new job, and settling at new sites.

\subsection{Advice at a naming ceremony}

At a naming ceremony, pieces of advice are given to the baby, parents and those gathered at the function. The child is advised to stay longer, the parents are advised to take proper care of the child, and the community is advised to support the parents in diverse ways to nurture the child into a responsible adult. These are based on the Akan communal spirit.

\section{Excerpt 4.}

Background: Naming Ceremony of a newly born baby

Place: Agbogba in Accra

Date: 21st September 2015

A newly born girl, whose parents are Kwadwo and Patience, was being named in the grandfather's house, and below is what transpired. I was at the function so I audio-taped the proceedings. The officiating elder put the child on his laps and said as follows: 


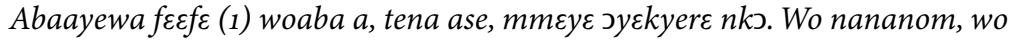
maamenom ne wo papanom, abusua ne ad Jfo nyinaa na ahyia ha nnedua yi. Ne tiawa ara ne se yerebema wo din na obiara hyia wo a, Jde afre wo. Edin a yede rema wo ne Nana Afia Agyekumwaa Adubofour. Yebefre wo Nana Afia tiawa, efiri

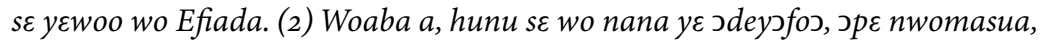

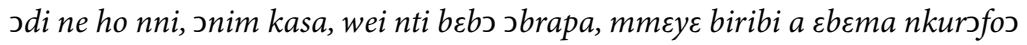
anya kwan adidi wo atsm ama ebi aka wo nana. (3) B $\mathrm{mm}$ oden na betiatia w'awofo anammon mu na yere wo ho besua adee na seesei nwomasua ne abrabว ne nkonimdie safoa. Ne korakora no Nana Afia

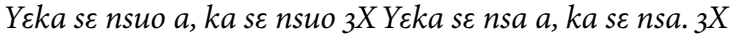

Ma wo aane, nye aane! Na wo daabi, nye daabi!

Onyame nhyira wo.(see a similar text in Agyekum 2006b:217)

English: Beautiful Baby, you are welcome to this world. (1) Have a longer stay, just do not come and exhibit yourself and return. Your grandparents, mothers, fathers, the entire family and beloved ones have assembled here today. In short, we are giving you a name so that when people meet you, they will call you by the name. We will call you Nana Afia Agyekumwaa Adubofour. You are named Afia because you were born on a Friday. ${ }^{4}$ Now that you have come to this world, (2) note that your grandmother is very industrious, she is interested in education, she is decent in character, she is an orator, therefore come and put up a good behaviour, you must not do anything that will allow people to insult you and be extended to your grandmother. (3) Try and follow the footsteps of your parents and strive to study very hard, because in current times, education is the key to success and good life. Finally, Nana Afia,

When we say water, let it be water!

When we say alcohol, let it be alcohol! Let your yes be yes!

And your no, be no! May God bless you!

\section{Analysis}

This excerpt is an elaborated advice where the officiating elder gives a background of the purpose of the gathering; the participants, including the family members and friends. Even though the child does not speak, the literary device of apostrophe is used and she is first advised; (a) to have a longer stay, and (b) not to just come and exhibit herself and return. This is based on the child mortality in Akan tradition where some children spent some few days and died. Akans, thus, wait for at least 7 days before they outdoor the child and name him. They believe that if the child survives after 7 days, he has surely come to stay.

4. Akans have automatic first name for females and males based on the days children are born. Friday borns are called Kofi (male) and Afia (female). (See Agyekum 2006b). 
The second directives are (a) you must not do anything that will allow people to insult you and be extended to your grandmother. (b) try and follow the footsteps of your parents and (c) strive to study very hard. A background is given about the character of the grandmother; the child is charged to replicate those morals, values and dignity to avoid tarnishing the family's reputation, and advised to study hard.

The final advice is on the value of truthfulness; this is symbolised by putting water and alcohol that look alike in colour but different in taste and functions. The child is instructed to be diligent and truthful throughout life. The advice employs Akan "advisory verbs" like note, do not, must not, strive, try to follow, and let it be. These carry counseling and persuasive tones to mitigate the directives encoded in the advice.

\subsection{Advice at a marriage ceremony}

In Akan, marriage is an important milestone that marks the process of adult life and procreation. During marriage ceremonies, elders from the bride and bridegroom families advise the young couple. They need what it takes to start and sustain a healthy family, which includes acquisition of properties, childbirth and respect for each other's family.

\section{Excerpt 5.}

There was a marriage ceremony at Asisiriwa in the Ashanti region between Lucy and Paddy on March 28th 2014. I witnessed the ceremony with both families, church members and friends. I audio-taped the proceedings, transcribed and translated it into English. The bride's father advised the couples using proverbs as follows.

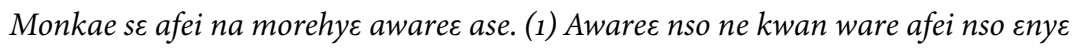

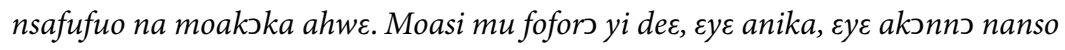

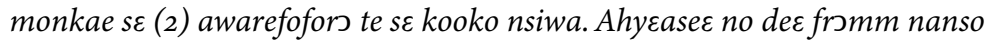
Entena ho saa daa. Mohia nkabom na moatumi abs brapapa anya bi ahwe mo mma daakye. Mpanin se (3) praes wo ho yi, woyi baako a, na ebuo, woka bom a,

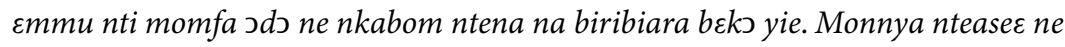
sd mmema mo ho. Onyame nhyira mo. Amen!

Remember that you are now starting the marriage. (1) 'Marriage's journey is long, again, 'marriage is not like palm wine to be tasted and spewed out.' Now that you have started the journey, it looks very enjoyable and appealing. But remember that (2) a new marriage is like a young cocoa farm that has started bearing fruits. The beginning is very gloomy but it will not remain so forever. You need cooperation to put up a prosperous life to cater for your children in the future. The elders say: (3) if you take out a single broom stick you can easily break it but if you put the sticks together you cannot break them, therefore live together with 
love and cooperation, and everything will be OK. Have love and understanding for each other. May God bless you! Amen!

The above advice, like the Akan stereotypical ones in marriage ceremonies, is full of symbolisms and proverbs. For instance, a new marriage is compared with a new gloomy cocoa farm, while cooperation is symbolised by a broom that cannot be broken because of unity. The two other proverbs are found in the Akan marital proverbs and pieces of advice on experiences and information on marriage (see Agyekum 2012). They forewarn the couple and their families on the experiences and problems in marriage and how to manage their affairs efficiently.

\subsection{Advice on reconciliation after settlement of disputes}

Agyekum $(2006 c, 366)$ records the advice after settlement of disputes in Akan and posits that such pieces of advice are meant for nkabom, 'reconciliation', one of the procedures in dispute settlement. Disputants may decide to embark on nsiesie, 'amicable settlements'. The Akans say mpanimfo atu wan nan asi asem no so, 'the elders have stamped their feet on the case', or yereka assm no abom, (lit.) 'we are joining the cases together' This formula differs from the traditional arbitration; here the disputants are not allowed to narrate their cases and there is no ruling. The elders give admonitions and pieces of advice to both parties to live peacefully but not as adversaries. The stereotypical advice is seen below.

\section{Excerpt 6.}

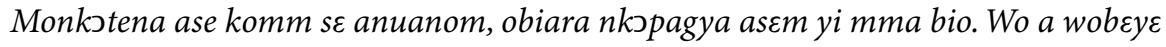
saa no, yene wo bedi no pa ara.

'You should go and stay peacefully like siblings. None of you should revisit the case. If any one does that, the elders will deal with him drastically.'

They are warned not to repeat such acts, or face the appropriate sanctions. Negotiations for peace and tranquility are popular in family and marital disputes. When there is a stalemate, the Akan jury seeks advice from the legendary old lady who is a custodian of wisdom, experience, peace, counselling, justice and fair resolution.

\subsection{Advice for a youth who is travelling (from Brako by Kwabena Adi)}

\section{Background}

The excerpt below is an advice from a father to his son who had completed his elementary education and was travelling to the capital city, Accra, to find some job. It 
is a holistic advice that covers hardwork, virtuous life, savings, consultations from knowledgeable people, and trust in the Lord. The father advised his son to avoid corruption, too many friendship, drunkenness, promiscuity and ungratefulness. What we find in this literature book are replicas of real life. The advice was full of proverbs and Akan advisory verbs; the proverbs are numbered sequentially and the advisory verbs are boldened. We will give a paragraph to paragraph English translation and then analyse the proverbs in the text.

a. "Adwumaye na worek ne ahofama. Minim se wonka mu wo eyinom biara mu. Nanso kae se, (1) dua a aboa no nsuro so no na owu da ase. Kae se (2) nokware di tuo. Fa boaseto ye wade nyinaa. Mma wo were mfi se, (3) wots wo bo gua atstea a, wuhu ne nsono ne n'akoma. Fa nsi ne anem ye w’ade se sbrakyereni ba. Mma w’ani mmere obi biribi da. Kae se, (4) okom de wo a, womfa wo nsa abien nnidi.

"You are entering into the job market. The essential things are honesty, calmness, discipline, humility and commitment. I know that you do not fall short in any of these. But remember that, (1) it is the tree that the animal is not afraid of that it dies under it. Remember that (2) honesty outwits a gun shot. Use patience to embark on all your activities. Do your work with diligence and propriety like the native of Obrakyere. Do not forget that, (3) if you take your time to dissect an ant you can see all the entrails. Do not be envious of anybody's property. Remember that, (4) if you are hungry you do not eat with both hands.

The father continued as follows:

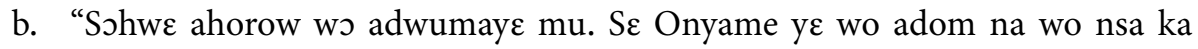
adwuma bi a sikasem w0 mu a, $h w \varepsilon$ na wo nsa anware wo sika a $\varepsilon$ beba wo nkyen no ho. Kae se (5) animguase mfata skanni ba. (6) Mmotohs ye syare. (7)

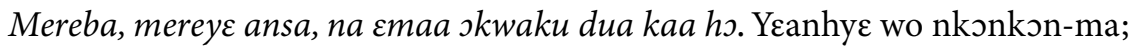
$\varepsilon n o$ nso nti minim se biribi nni ho a wubehyia a, ebebu afa wabasa so. Nanso manya no nhui, enti na masem reye aware no. (8) Nim saa anka, nnii kan da. (9) Obi nhu nanka, nyaa nanka na эnse se, mihui a, anka. Eno nti $h w \varepsilon$ na obi anto wo semmrada annaadaa wo na woanka se minim saa a, anka. $H w \varepsilon$ na to wo tekrema nnareka. Kae se (10) tekremakam sen oyiwankam. Bo mmoden se wobstwe wo ho afi otekremafo ho. Suro nea ow tekremakyene; oka asem fen-

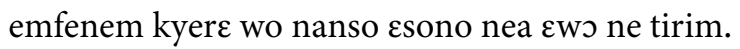

"There are many temptations at worksite. If by the grace of God you get some financial job, ensure that your hands are not very long on the monies that come your way. (5) Note that disgrace does not befit an Akan. (6) Procrastination is a disease. (7) I will be here in a moment, I am waiting for a while, is 
what made the monkey's tail remain there forever. Whatever you have to do, do it promptly and earnestly. We did not treat you as a pampered child so I know that there is no encounter that can outwit you. But I am aware, that is why I am talking too much. (8) Had I known is always at last. (9) Nobody sees the puff adder (snake) and leaves it to go scot-free and then complains that if I had known, I would have killed it. So make sure that nobody persuades and swindles you for you to remark "I should have known." See to keep your tongue tight. (10) Remember that the scar from the tongue is more dangerous than that from a razor. Try to shun swindlers. Be afraid of a "salty tongue person", he speaks so nicely to you but harbours something different in his head.

The advice now moves to the need for consultation and counselling when in difficulties by seeking the expertise of elders.

c. "Se biribi kyere wo so den wo a, hwehwe sbadwemma bi na fa to n'anim. (11) Kae se, me nko me tirim porsw. Bio hwe na woamfa wo ho anhyehye nkurofo nsem mu. Se wo bra ye a, wubenya spanyin bi aso wo mu abia. (12) Kae se abJfra hu ne nsa hohoro a, one mpanyin to nsa didi.

"If you are hard pressed, search for an intelligent person and put your case before him. (11) Remember that, it is not fruitful to think solely. Again, be careful not to mingle yourself in people's affairs. If you put up a good behaviour you will get an elder to support you. (12) Remember that if the child knows how to wash his hands. he eats with the elders.

\section{Analysis of Akora Hwعwodęso's advice}

The analysis of this advice focuses on proverbs, metaphors, and idioms, which are important aspects of Akan ethnographic communication. The father provided narrative contexts based on Akan ethnopragmatics to support the advice.

The context, structure and style of Akan advice may differ from the western cultures. In the above advice, proverbs, explanation, analogies, symbolism, (core ingredients in Akan narratives) are used so that the adviser can interact successfully with the advisee, persuade and direct him accordingly. There is coherence in the narration so as to provide a clear information and purpose; the accurate picture of the advice and use of proverbs make it more meaningful and authoritative.

\subsection{Proverbs and metaphors in Akan advice}

The adviser embarks on proverbs and metaphors that have direct advisory effects on the advisee. This advisory text has 12 proverbs based on Akan traditional 
experiences, philosophy, cultural knowledge, ideology and wisdom. These are coupled with intimacy, power from the father, and the urgency of the advice, since the son was travelling to the city with heterogeneous people and diverse characters. The first advice is based on cautiousness and not taking things for granted. An analogy is provided by pointing to animals that display foolhardiness and eventually die under trees they disregard as dangerous. The second and third proverbs centre on the strengths in honesty and patience, and how honesty can outwit the gun, the most dangerous weapon. Patience acts like a microscope that gives insight into everything including, dissecting an ant and seeing its entrails. This may seem hyperbolic, but in Akan ethnopragmatics it focuses on cautiousness and being meticulous.

The fourth proverb highlights greediness. Instead of telling the advisee directly to refrain from greediness, the adviser politely couched this in a proverb, "no matter how hungry you are, you cannot eat with both hands." Culturally, Akans eat using only their right hands. To use both hands when eating in the same bowl with others implies greediness, and denying others of the food; this violates the Akan communal spirit.

The fifth proverb enjoins the son to refrain from acts that will disgrace him and the entire Akans, hence animguaese mfata skanni ba, 'disgrace does not befit an Akan.' The Akans cherish politeness and want to do things that will raise their image, and this cultural ideology is part of enculturation. The two subsequent parallel proverbs advise the young man to be conscious of time, and respect dead-

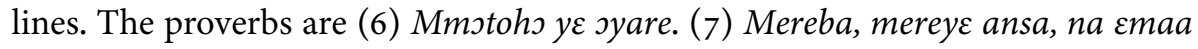
skwaku dua kaa ho. "Procrastination is a disease." "I will be here in a moment; I am waiting for a while is what made the monkey's tail remain there forever." There is an analogy between procrastination and disease; because when you procrastinate the work is left undone; similarly when you are sick you cannot do what is expected of you. Procrastination is inexcusable, but one can make an appeal based on sickness. The parallel proverb is 'procrastination is what made the monkey's tail remain there forever. If you procrastinate you may lose things for ever.

The next parallel proverbs indicate the consequences of failing to act appropriately and they are (8) Nim saa anka nnii kan da. (9) Obi nhu nanka, nnyaa nanka na onse se, mihui a, anka. 'Had I known has never been at the first position.' 'Nobody sees the puff adder (snake) and leaves it to go scot-free and then complains that if I had known, I would have killed it.' If one decides too late, no action can be taken. The ninth proverb is in a pun and assonance using the vowel letter [a] in the words anka, a modal meaning, 'had it been', nanka, 'puffer adder', and nnyaa 'does not leave'.

The tenth proverb enjoins the advisee to be mindful of his language and this is captured in the metaphor of the tongue and razor as in: Kae se tekrema kam 
sen onyiwan kam. 'Remember that 'the scar from the tongue is more dangerous than one from a razor.' The Akans believe that a wound resulting from a razor-cut will definitely get healed no matter how long it takes. This proverb alludes to the potency of the tongue and the power of the spoken word. A wound from a razorcut affects the person alone; however, if the tongue slips and uses invectives, it travels wider; the words become indelible and will never be forgotten across generations. Some conflicts among individuals, societies, parties, etc. have stemmed from unguarded and intemperate language (see Agyekum 2018). In effect, the Akans want their children to be communicatively competent in all socio-cultural interactions.

In proverb 11, Kae se, me nko me tirim porsw. 'Remember that, it is not fruitful to think solely'. Attention is drawn to consultation using the metaphor of a rotten head. In Akan culture, when you refuse to discuss issues with people and you habour everything, positive or negative, the brain conceptually becomes rotten. Consultation and seeking advice from others is the most optimum thing to do. Proverb 12 advises the youth to put up good behaviour so that they can interact with the elders and acquire their rich experiences. This is captured by the proverb Kae se abJfra hu ne nsa hohoro a, one mpanyin to nsa didi. Remember that 'if the child knows how to wash his hands, he eats with the elders.'

We have noted the pervasive use of the verb kae, 'remember' in the proverbs; it prefaces five out of the twelve advisory proverbs; it draws the advisee's attention to existing cultural truism and the authoritative source embedded in the Akan proverbs. ${ }^{5}$ Examples of such proverbs are (i) Kae se (2) nokware di tuo. Remember that 'honesty outwits a gun short.' (ii) Kae se, (4) $\mathrm{oksm}$ de wo a, womfa wo nsa abien nnidi. 'Remember that, 'if you are hungry you do not eat with both hands.' (iii) Kae se (10) tekremakam sen oyiwankam. Remember that 'the scar from the tongue is more dangerous than that from a razor', (iv) Kae se (11) me nko me tirim porsw. Remember that, 'it is not fruitful to think alone. (Thinking on your own, rots your mind). (v) Kae se (12) absfra hu ne nsa hohoro a, one mpanyin to nsa didi. Remember that if the child knows how to wash his hands, he eats with the elders.' Proverbs 6 and 7 and 7 and 8 were parallel proverbs meant for emphasis.

5. The verb kae triggers the interpretive marker $s \varepsilon$, 'that' used to mark thoughts and utterances (see Agyekum (2002; 128). Akan, proverbs, wise sayings, adages of philosophical thoughts and reported speech are initiated with $s \varepsilon$, 'that'. 


\section{Conclusion}

In this paper, we have discussed Akan advice from the point of ethnopragmatics, directives, expressives, persuasion and proverbs. We noted that the ethnosemantics of afotuo 'advice; in Akan can stand for advice, suggestion, exhortation, admonition, counselling, preaching, encouragement, and a plea. It has the NSM and cultural scripts' core meaning "It will be good if after this you do this."

In Akan, the channel of pieces of advice in advisory communicative event is mostly unidirectional; it transcends from an adult to the youth, the rich to the poor, and not the reverse. It could be between a husband and wife or between coworkers. Most Akan pieces of advice are formulaic and more predictable; examples are naming and marriage ceremonies and settlement of cases. We saw that Akan advice normally shows the acquaintances, solidarity, rapport, and group belongingness of the adviser and the advisee. Due to the communal nature of Akan society, advice is part of our linguistic routines and sociocultural values.

In using advice within ethnopragmatics from a "cultural-insider's" competence and expressives, advice is a representative and interpretation of the psychological inner state of the speaker directed to the addressee. An adviser expresses some advisory actions he deems fit to the advisee and expects a positive result. The adviser directs, orders, requests, suggests and appeals to the advisee towards a posterior action or change of behaviour. He may caution and appeal to the advisee to take note, remember, ensure, be mindful, to do things that are very beneficial.

We observed the cleverly and skillful manner that advisers use proverbs; because Akan proverbs have authoritative sources from experienced elders whose statements are incontestable. The advisers further employ explanations, metaphors, and symbolisms to interact successfully with the advisees and draw some analogies using flora and fauna based on Akan socio-cultural values and ethnopragmatics.

We considered advice as one of the linguistic routines among the Akans that is handled with politeness and persuasive language. To achieve the purpose of advice, the advisee must accept it wholeheartedly. In Akan ethnopragmatics, a piece of advice is incomplete if it is considered as a face-threat and therefore rejected. Even though advice is a universal concept, it is administered in specific and unique sociocultural modes, and in Akan, proverbs play a central role in advice as noticed in this paper. Unlike English and other western cultures, Akan advice is not considered an imposition but an appeal, a concern and counselling based on Akan communalistic society.

With influence from western cultures and human rights some Akan youth have become recalcitrant and sometimes see advice as imposition and infiltration into their privacy and thus decline to accept and abide by it. This tallies with 
Anglo-Saxon experiences recorded by Larina (2009). With modernization, western education, Christianity and Islam, pieces of advice have been shifted from the family and parental levels to the hands of professional counselors, TV and Radio counselors, pastors and sheiks. Further studies should look at advice in the traditional and social media.

\section{References}

Adi, Kwabena. 1973. Brako. Tema: Ghana Publishing Corporation.

Agyekum, Kofi. 2018. Akan Body Parts Expressions: A Cognitive Semantics and Pragmatic Approach. Accra: Adwinsa Publications Ltd.

Agyekum, Kofi. 2012. "Akan Proverbs and Aphorisms about Marriage." Research Review NS 27 (2): $1-24$.

Agyekum, Kofi. 2010. “The Sociolinguistics of Thanking in Akan.” Nordic Journal of African Studies 19 (2): 77-97.

Agyekum, Kofi. 2008. “The Pragmatics of Akan Greetings. Discourse Studies 10 (4): 489-512. https://doi.org/10.1177/1461445608091884

Agyekum, Kofi. 2006a. "Akan Apology: A Repair Mechanism in Akan Social Interaction." South African Journal of Linguistics 26 (2): 53-68.

Agyekum, Kofi. 2006b. “The Sociolinguistic of Akan Personal Names." Nordic Journal of African Studies 15 (2): 206-235.

Agyekum, Kofi. 2006c. "Akan Traditional Arbitration: Its Structure and Language." Journal of Multilingual and Multicultural Development 27 (5): 359-74. https://doi.org/10.2167/jmmd428.1

Agyekum, Kofi. 2005. “The Pragmatics of Requests in Akan Communication.” Legon Journal of Humanities 16: 1-26.

Agyekum, Kofi. 2004a. “The Sociocultural Concept of Face in Akan Communication.” Journal of Pragmatics and Cognition 12 (1): 71-92. https://doi.org/10.1075/pc.12.1.06agy

Agyekum, Kofi. 2004b. "Aspects of Persuasion in Akan Communication." International Journal of Language and Communication RASK 2: 63-96.

Agyekum, Kofi. 2002. “The Interpretive Marker Se in Akan.” In New Directions in Ghanaian Linguistics, ed. by Felix K. Ameka, and Emmanuel K. Osam, 127-145. Accra: Black Mask Publishers.

Ameka, Felix. 2009. “Access Rituals in West African Communities: An Ethnopragmatic Perspective." In Ritual Communication, ed. by Gunther Senft and Ellen B. Basso, 127-152. New York: Berg.

Ameka, Felix. 2006. "When I Die, Don't Cry': The Ethnopragmatics of “Gratitude” in West African Languages. In Ethnopragmatics: Understanding Discourse in Cultural Context, ed. by Cliff Goddard, 231-266. Berlin: Mouton De Gruyter. https://doi.org/10.1515/9783110911114.231

Ameka, Felix, and Breedveld, Anneke. 2004. "Areal Cultural Scripts for Social Interaction in West African Communities?” Intercultural Pragmatics 1-2: 167-187.

Christaller, Johannes G. 1933. Dictionary of the Asante and Fante Language Called Tshi (Twi). 2nd Edition. Basel: The Basel Evangelical Missionary Society. 
Duranti, Allesandro. 1997. Linguistic Anthropology. Cambridge: Cambridge University Press. https://doi.org/10.1017/CBO9780511810190

Goddard, Cliff. 2006. “Ethnopragmatics: A New Paradigm.” In Ethnopragmatics:

Understanding Discourse in Cultural Context, ed. by Cliff, Goddard, 1-30. Berlin: Mouton De Gruyter. https://doi.org/10.1515/9783110911114.1

Goddard, Cliff. 2004. “The Ethnopragmatics and Semantics of 'Active Metaphors.” Journal of Pragmatics (Special issue on 'Metaphor', ed. by Gerard Steen) 36 (7): 1211-1230. https://doi.org/10.1016/j.pragma.2003.10.011

Goddard, Cliff, and Wierzbicka, Anna. 2004. "Cultural Scripts: What are They and What are They Good for?” Intercultural Pragmatics 1-2: 153-166.

Goddard, Cliff, and Ye, Zhengdao. 2015. “Ethnopragmatics.” In The Routledge Handbook of Language and Culture, ed. by Sharifian, Farzad, 66-83. London: Routledge.

Jefferson, Gail, and Lee, John R.E. 1981. "The Rejection of Advice. Managing the Problematic Convergence of a Troubles-Telling and a Service Encounter." Journal of Pragmatics 5: 399-422. https://doi.org/10.1016/0378-2166(81)90026-6

Larina, T. (2009). The Categories of Politeness and the Style of Communication. A Comparison of the English and Russian Lingua-Cultural Traditions [In Russian] Moscow: Slavic Language and Culture Publishers. (Moskva: Jazyki Slavjanskix Kultur).

Mey, Jacob L. 2001. Pragmatics: An Introduction, 2nd Edition. Oxford. Blackwell.

Obeng, Gyasi Samuel. 1999. "Apologies in Akan Discourse." Journal of Pragmatics 31: 709-734. https://doi.org/10.1016/S0378-2166(98)00089-7

Obeng, Gyasi Samuel. 1987. Conversational Strategies: Towards a Phonological Description of Projection in Akyem. Unpublished Ph. D Thesis, York Univ. UK.

Searle, John R. 2009. "Searle's Felicity Conditions on Speech Acts." In Concise Encyclopedia of Pragmatics, 2nd Edition, ed. by Jacob L. Mey, 1004-1009. Amsterdam: Elsevier Ltd.

Sharifian, Farzad. 2017. Cultural Linguistics. Amsterdam: John Benjamins. https://doi.org/10.1075/clscc.8

Sharifian, Farzad. 2015. "Cultural Linguistics." In The Routledge Handbook of Language and Culture, ed. by Sharifian Farzad, 473-49o. London: Routledge.

Tsurikova, Lyubov, and Evanson, Virginia. 1995. "Advice: A Pragmatic Approach to Teaching Functions in English.” Revista de Lenguas Ara Fines Especificos. 2: 14-22.

Wierzbicka, Anna. 2015. "Language and Cultural Scripts." In The Routledge Handbook of Language and Culture, ed. by Sharifian Farzad, 339-356. London: Routledge.

Wierzbicka, Anna. 2012. "Advice in English and Russian: A Contrastive and Cross-Cultural Perspective." In Advice in Discourse, ed. by Limberg Holger and Miriam A. Locher, 309-332. Amsterdam: John Benjamins. https://doi.org/10.1075/pbns.221.19wie

Wierzbicka, Anna. 1991. Cross-Cultural Pragmatics: The Semantics of Human Interaction. Berlin: Mouton de Gruyter.

Yankah, Kwesi. 1995. Speaking for the Chief: Okyeame and the Politics of Akan Royal Oratory. Bloomington: Indiana University Press.

Yankah, Kwesi. 1991. "Orality in Akan Society." Discourse and Society 2(1):47-64. https://doi.org/10.1177/0957926591002001003

Yankah, Kwesi. 1989. "Proverbs: The Aesthetics of Traditional Communication." Research in African Literature 20(3):325-346.

Yule, George. 200o. Pragmatics. Oxford: Oxford University Press. 


\section{Address for correspondence}

Kofi Agyekum, Ph.D.

University of Ghana, Legon-Accra

Department of Linguistics

P. O. Box 61

Ghana- West Africa

kagyekum@ug.edu.ug.gh

\section{Biographical notes}

Kofi Agyekum is a Professor of Linguistics and the current Dean of the School of Performing Arts, University of Ghana. His areas of interest are Pragmatics, Discourse Analysis, Ethnography of Communication, Anthropological Linguistics, Language and Culture, Sociolinguistics, Stylistics, Semantics, Translation, Lexicology, Oral and Written Literature, and Terminology. He has lectured and researched in these fields. He is a renowned Akan scholar and broadcaster, and has contributed significantly to the development of the Akan language in both the academic and broadcasting fields. He has published many books, and has articles in various international and local journals, including, Legon Journal of Humanities, Pragmatics and Cognition, Pragmatics (IPrA), International Journal of Language and Communication (RASK), Metaphor and the Social World, Language and Dialogue, Discourse Studies, Sociolinguistics Studies, Journal of Language and Politics, and Journal of Anthropological Research. He has received many national and institutional awards for his contribution to language, culture, education and the media.

(ID) https://orcid.org/00oo-0002-6177-2819

\section{Publication history}

Date received: 3 January 2017

Date accepted: 28 January 2019

Published online: 25 June 2019 